\title{
Structural genomic variation in childhood epilepsies with complex phenotypes
}

\author{
Ingo Helbig ${ }^{\star, 1}$, Marielle EM Swinkels ${ }^{2,3}$, Emmelien Aten ${ }^{4}$, Almuth Caliebe ${ }^{5}$, Ruben van 't Slot ${ }^{2}$, Rainer Boor', \\ Sarah von Spiczak ${ }^{1}$, Hiltrud Muhle ${ }^{1}$, Johanna A Jähn ${ }^{1}$, Ellen van Binsbergen ${ }^{2}$, Onno van Nieuwenhuizen ${ }^{6}$, \\ Floor E Jansen ${ }^{6}$, Kees PJ Braun ${ }^{6}$, Gerrit-Jan de $\mathrm{Haan}^{3}$, Niels Tommerup ${ }^{7}$, Ulrich Stephani ${ }^{1}$, Helle Hjalgrim ${ }^{8,9}$, \\ Martin Poot $^{2}$, Dick Lindhout ${ }^{2,3}$, Eva H Brilstra ${ }^{2}$, Rikke S Møller ${ }^{7,8}$ and Bobby PC Koeleman ${ }^{2}$
}

\begin{abstract}
A genetic contribution to a broad range of epilepsies has been postulated, and particularly copy number variations (CNVs) have emerged as significant genetic risk factors. However, the role of CNVs in patients with epilepsies with complex phenotypes is not known. Therefore, we investigated the role of CNVs in patients with unclassified epilepsies and complex phenotypes. A total of 222 patients from three European countries, including patients with structural lesions on magnetic resonance imaging (MRI), dysmorphic features, and multiple congenital anomalies, were clinically evaluated and screened for CNVs. MRI findings including acquired or developmental lesions and patient characteristics were subdivided and analyzed in subgroups. MRI data were available for $88.3 \%$ of patients, of whom $41.6 \%$ had abnormal MRI findings. Eighty-eight rare CNVs were discovered in 71 out of 222 patients (31.9\%). Segregation of all identified variants could be assessed in 42 patients, 11 of which were de novo. The frequency of all structural variants and de novo variants was not statistically different between patients with or without MRI abnormalities or MRI subcategories. Patients with dysmorphic features were more likely to carry a rare CNV. Genome-wide screening methods for rare CNVs may provide clues for the genetic etiology in patients with a broader range of epilepsies than previously anticipated, including in patients with various brain anomalies detectable by MRI. Performing genome-wide screens for rare CNVs can be a valuable contribution to the routine diagnostic workup in patients with a broad range of childhood epilepsies.
\end{abstract}

European Journal of Human Genetics (2014) 22, 896-901; doi:10.1038/ejhg.2013.262; published online 27 November 2013

Keywords: CNV; structural genomic variation; childhood epilepsies; epileptic encephalopathies

\section{INTRODUCTION}

Epilepsies are frequent neurological disorders with a strong genetic component. ${ }^{1}$ Decades of intense research have led to the discovery of several epilepsy genes, for which genetic testing can provide early diagnosis and guide optimal treatment. However, the genetic basis for the majority of refractory and childhood-onset epilepsies remains elusive. Many patients have epilepsies with complex phenotypes that are difficult to classify, sometimes with definite or questionable magnetic resonance imaging (MRI) abnormalities ranging from nonspecific findings to clear developmental abnormalities, some degree of dysmorphic features, mild-to-severe intellectual disability or psychiatric comorbidities.

Various classifications can be used to describe the epilepsy phenotypes in these patients, including the 1989 and 2010 classification of the International League Against Epilepsy (ILAE). ${ }^{2,3}$ However, the rare complex phenotypes including possible dysmorphic features, intellectual disability, and questionable or nonspecific MRI findings are sometimes not fully captured in either classification. We used existing 1989 ILAE categories for patients if possible, acknowledging that a large fraction of patients were difficult to classify. For some syndromes, we also use the current 2010 ILAE classification. We refer to the overall cohort as epilepsies with complex phenotypes.

Although this patient group represents a significant fraction of patients referred for genetic counseling, causative genetic alterations in known genes for monogenic seizure disorders are only identified in a small subset. Also, patients with these complex phenotypes are usually not included in current large-scale genetic studies. Accordingly, these epilepsies represent 'forgotten phenotypes', and gene discovery in this group of patients is pressing and of major importance.

Copy number variations (CNVs) including microdeletions and microduplications have emerged as a new pathogenic principle in a range of neurological and psychiatric disorders in recent years. Genome-wide screens of focal and generalized epilepsy have identified recurrent microdeletions in up to $3 \%$ of patients with idiopathic generalized epilepsies (also genetic generalized epilepsies) and in $1 \%$ of focal epilepsies. ${ }^{4,5}$ Microdeletions at the chromosomal regions $15 \mathrm{q} 13.3$ and $16 \mathrm{p} 13.11$ are the most frequently identified variants,

${ }^{1}$ Department of Neuropediatrics, University Medical Center Schleswig-Holstein (UKSH), Kiel, Germany; ${ }^{2}$ Department of Medical Genetics, University Medical Center Utrecht, Utrecht, The Netherlands; ${ }^{3}$ SEIN Epilepsy Institute in the Netherlands Foundation, Hoofddorp, The Netherlands; ${ }^{4}$ Department of Medical Genetics, Leiden University Medical Center, Leiden, The Netherlands; ${ }^{5}$ Department of Human Genetics, University Medical Center Schleswig-Holstein (UKSH), Kiel, Germany; ${ }^{6}$ Department of Child Neurology, Rudolf Magnus Institute of Neurosciences, University Medical Center Utrecht, The Netherlands; ${ }^{7}$ Wilhelm Johannsen Centre for Functional Genome Research, Copenhagen, Denmark; ${ }^{8}$ Danish Epilepsy Centre, Dianalund, Denmark; ${ }^{9}$ Institute of Regional Health Services Research, University of Southern Denmark, Odense, Denmark

${ }^{*}$ Correspondence: Professor I Helbig, Department of Neuropediatrics, University Medical Center Schleswig-Holstein (UKSH), Building 9, Arnold-Heller-Street 3, D-24105 Kiel, Germany. Tel: +49 (0) 431597 1622; Fax: +49 (0) 431597 1769; E-mail: i.helbig@pedneuro.uni-kiel.de

Received 27 January 2013; revised 1 October 2013; accepted 18 October 2013; published online 27 November 2013 
which are clearly established genetic risk factors for epilepsy. However, contribution to disease is modest, and carriers may present with variable phenotypes including a broad spectrum of different epilepsy subtypes, various neurodevelopmental disorders, and severe syndromes with multiple congenital anomalies (MCAs). Furthermore, these microdeletions are often transmitted from a healthy parent, illustrating the complexity of the underlying genetic architecture and disease mechanism. ${ }^{5-7}$ In addition to recurrent $\mathrm{CNVs}$, up to $10 \%$ of patients with various epilepsies carry a unique and possibly pathogenic $\mathrm{CNV}^{4}$ Although many of these variants may represent benign variants, the overall $\mathrm{CNV}$ burden in this group is clearly elevated as compared with control populations, ${ }^{8}$ indicating that at least some of these variants are genetic risk factors.

The role of microdeletions and microduplications in seizure disorders extending beyond the group of well-classified non-lesional and non-syndromal epilepsies remains unclear. We therefore sought to investigate the rate of rare and recurrent CNVs in a large sample of cases with a complex epilepsy phenotype, including patients with or without intellectual disability, dysmorphic features, or MRI abnormalities. Most of these patients would have been classified as having symptomatic epilepsy in the 1989 ILAE classification.

\section{MATERIALS AND METHODS}

\section{Clinical phenotyping}

Patients were recruited from three centers, including two epilepsy centers (Kiel, Dianalund) and one clinical genetics center (Utrecht). In accordance with the overall aim of the study, the inclusion criteria were designed to allow for a selection of a highly diverse patient population with rare epilepsy phenotypes, which are usually not included in genetic studies either because of the phenotype or owing to the presence of abnormalities on MRI.

Patients for this study were selected on the basis of the following criteria: (1) rare epilepsies, which were not easily classified into existing common epilepsy syndromes such as Idiopathic/Genetic Generalized Epilepsy or Benign Rolandic Epilepsy, even though atypical presentations of common epilepsies were included; and (2) availability of MRI data on patients. The presence of apparently acquired lesions was not used as an exclusion criterion, as long as a genetic component was considered by the referring physicians - for example, when the seizure disorder was too severe or not typical for the type of lesion, or the pathology of the lesion was not clear. The study was approved by the local ethics boards at the University of Kiel, the Danish Epilepsy Center Dianalund, and the University of Utrecht.

\section{MRI classification}

Available information on MRI was included. MRI findings were divided into acquired or developmental lesions or nonspecific abnormalities. The developmental lesions were further subdivided into malformations of cortical development ${ }^{9}$ and other lesions.

\section{Genetic analysis}

Patients from the center at Utrecht were genotyped using an Agilent 105K/ $180 \mathrm{~K}$ comparative genomic hybridization (CGH) array and analyzed with the standard software provided by the manufacturer (Agilent Technologies, Inc., Santa Clara, CA, USA). Patients from the centers at Dianalund and Kiel were genotyped with Affymetrix 6.0 arrays and analyzed with the Affymetrix Genotyping Console (Affymetrix, Illumina, San Diego, CA, USA). The structural genomic variations for the entire sample were included in the analysis if the variant (1) was larger than $100 \mathrm{~kb}$, (2) overlapped with a known gene, and (3a) did not overlap with a benign CNV in the Database of Genomic Variants or (3b) overlapped with previously reported pathogenic CNVs. For a subset of patients, parents were available for segregation analysis. CNVs were classified as pathogenic variants, likely pathogenic variants or as variants of unknown significance according to established guidelines. ${ }^{10}$ In brief, CNVs were considered pathogenic if they represented de novo deletions or known deletions associated with human epilepsies. Likely pathogenic variants were de novo duplications and
CNVs larger than $1 \mathrm{Mb}$ that were inherited or of unknown inheritance. All other CNVs were considered of unknown significance.

Variants were annotated in hg19 as a reference sequence. Some arrays were analyzed based on hg18, which is indicated in the overall variant list (Supplementary 1 and 2).

\section{Statistical analysis}

Statistical analysis was performed with the R Statistical Package (http://www.rproject.org). Fisher's exact test was applied when appropriate. All tests were two-sided; confidence intervals and odds ratios were reported as appropriate.

\section{RESULTS}

\section{Cohorts}

The patient sample included 223 patients (129 male and 94 female patients) from the three participating centers (Utrecht $n=155$, Dianalund $n=39$, Kiel $n=29$ ). The epilepsy phenotypes of the patients are shown in Table 1. A total of 137 patients were classified as having lesional or presumably lesional or structural epilepsy according to the most recent classification by the ILAE. ${ }^{10}$ The frequencies of MRI abnormalities, dysmorphic features, multiple congenital abnormalities, intellectual disability, and other neurodevelopmental disorders are outlined in the sections below.

\section{Overall frequency of rare structural variants}

We identified 88 rare CNVs exceeding $100 \mathrm{~kb}$ in 71 patients $(31.8 \%$, Supplementary Table 1). A female patient with monosomy of the $\mathrm{X}$ chromosome was excluded from further analysis of rare structural variants (patient NL69, see below 'other genetic findings'). An additional 19 variants smaller than $100 \mathrm{~kb}$ in size were detected in 19 patients (including six patients with additional larger variants) using the higher resolution of the array-CGH platform from the Utrecht center (Supplementary Table 2). Only one of these variants representing a deletion (patient NL8) was de novo (see below 'CNVs with additional mutations'). We further focused on the variants larger than $100 \mathrm{~kb}$ to allow for comparability between platforms. A total of 18 out of 88 variants were considered pathogenic including 10 de novo deletions, whereas 15 out of 88 variants were considered likely pathogenic and 55 out of 88 variants were of unknown significance, including 17 deletions and 38 duplications (ratio $\sim 1: 2$ ). The 88 variants were distributed in the 71 patients with identified variants as follows: 18 out of 71 patients carried at least a single pathogenic variant, 12 out of 71 patients carried at least a single likely pathogenic variant, and 41 out of 71 patients carried at least a single variant of unknown significance; 57 out of 71 patients had a single rare variant (15 pathogenic, 7 likely pathogenic, 35 unknown significance), 11 out of 71 patients had two variants and 3 patients had three variants. The median size of all variants was $410 \mathrm{~kb}$ (range $102 \mathrm{~kb}$ to $12.7 \mathrm{Mb}$ ). The size of 25 variants was between 100 and $200 \mathrm{~kb}$ (28.4\%), 27 variants were between 200 and $500 \mathrm{~kb}(30.6 \%), 13$ variants ranged between $500 \mathrm{~kb}$ and $1 \mathrm{Mb}(14.8 \%), 19$ variants were between 1 and $3 \mathrm{Mb}(21.6 \%)$ and 4 variants were larger than $3 \mathrm{Mb}(4.6 \%)$. All four variants larger than $3 \mathrm{Mb}$ were de novo. Segregation of all identified variants could be assessed in 42 out of 71 patients, and 11 of these patients had at least a single de novo variant (26.1\%, Table 2$)$.

\section{CNVs in genomic hotspots}

$\mathrm{CNV}$ in genomic hot-spot regions of the human genome ${ }^{11}$ were identified in 11 out of 223 patients $(4.9 \%)$ and were considered pathogenic (Table 3). Duplications at $1 \mathrm{q} 21.1$ and $16 \mathrm{p} 13.11$ were found in one patient each. Similarly, microdeletions at $15 \mathrm{q} 13.3$ and $22 \mathrm{q} 11.2$ were detected in a single patient each. Microdeletions at 
Table 1 Epilepsy phenotypes

\begin{tabular}{lcc}
\hline Epilepsy syndrome & \multicolumn{3}{c}{$\begin{array}{c}\text { Genetic findings } \\
\text { before inclusion in study }\end{array}$} \\
\hline Distinct rare epilepsy syndromes or epileptic & $\mathrm{n}$ encephalopathies \\
Ohtahara syndrome & 2 & \\
BFNS & 1 & KCNQ2 del \\
MMPSI & 1 & \\
West Syndrome & 30 & DMD del \\
LGS $(n=1)$ \\
Dravet syndrome & 9 & \\
ABPE (Pseudo-Lennox syndrome) & 3 & SCN1A $(n=2)$ \\
CSWS & 3 & \\
Landau-Kleffner syndrome & 13 & \\
& 1 & \\
Generalized epilepsies & & \\
GGE & & \\
MAE & 13 & \\
PME & 5 &
\end{tabular}

Lesional epilepsies (symptomatic focal and generalized epilepsies)

Symptomatic focal epilepsy 75

Symptomatic generalized epilepsyc 2

Symptomatic epilepsy, unclassified ${ }^{\mathrm{d}}$ and/or 60 m.3243A $>\mathrm{G}^{\mathrm{e}}(n=1) D M D$ presumably lesional

$\mathrm{del}^{\mathrm{a}}(n=1)$

Abbreviations: ABPE, atypical benign partial epilepsy; BFNS, benign familial neonatal seizures; CSWS, continuous spikes and waves during slow sleep; GGE, genetic generalized epilepsies; LGS, Lennox-Gastaut syndrome; MAE, myoclonic astatic epilepsy; MMPSI, malignant migrating partial seizures of infancy; PME, progressive myoclonus epilepsy.

apatients NL41 and D16 carried a maternally transmitted deletion of DMD, which was considered unrelated to the epilepsy phenotype.

considered unrelated to the epilepsy phenotype. Patients with apparent idiopathic generalized epilepsy phenotypes,
findings, dysmorphic features, or abnormal clinical examination.

cEpilepsies not easily classified into distinct electroclinical syndromes such as West Syndrome

or LGS.

${ }^{d}$ Including patient NL69 with a monosomy of the X-chromosome compatible with Turner Syndrome.

eMitochondrial mutation related to MELAS (mitochondirial encephalomyelopathy, lactic acidosis, and stroke-like episodes).

$15 \mathrm{q} 11.2{ }^{6} 16 \mathrm{p} 13.11,{ }^{12}$ and $16 \mathrm{p} 11.2^{13}$ were observed in two patients each. Finally, one patient with unclassified focal epilepsy had a de novo $17 \mathrm{p} 11.2$ deletion consistent with the Smith-Magenis syndrome (SMS).

\section{CNVs with additional mutations}

Five patients with an additional monogenic cause for their epilepsy were identified in the cohort. All five patients carried a candidate $\mathrm{CNV}$ in addition to the disease-related monogenic variant, including one pathogenic variant and four variants of unknown significance. Two patients (NL9, NL23) had Dravet syndrome with mutations in SCN1A and carried duplications of unknown significance. Early in the course of the disease, patient NL9 did not show the typical presentation of Dravet syndrome, which prompted array-CGH analysis in addition to SCN1A testing. A previously unknown duplication at $14 \mathrm{q} 22.1 \mathrm{q} 22.2$ spanning the GNG2 gene was identified through array-CGH. In patient NL23, array-CGH showing a paternally inherited duplication at 2q21.3 was performed because of microcephaly, a cleft lip and cleft palate in addition to clinical features of Dravet syndrome. Furthermore, patient NL60 with a maternally inherited duplication at 2q32.1 (unknown significance) was diagnosed with mitochondrial encephalomyopathy, lactic acidosis, and stroke-like episodes (MELAS) after array-CGH, and was seen to be carrying a common MELAS-related mutation in the mitochondrial DNA (m.3243A > G). Patient NL62 had familial benign neonatal seizures with a deletion of KCNQ2; array-CGH was performed to assess the size of the deletion and an additional 15q11.2 deletion was identified (pathogenic variant). In patient NL18, the diagnosis of Tuberous Sclerosis Complex was made after array-CGH had been performed, which showed a maternally inherited duplication at 4q32.1 (unknown significance). In all five patients, array-CGH would not have been performed if the positive genetic finding had been detected before array-CGH. This suggests that array-CGH may be considered a part of the diagnostic workup in patients with known mutations if atypical clinical findings are present. Finally, two male patients NL41 and D16 carried inherited deletions of the DMD gene compatible with Duchenne muscular dystrophy. Although considered explanatory for the muscular symptoms, the association with the epilepsy phenotype is uncertain. Patient NL69 had monosomy of the $\mathrm{X}$ chromosome compatible with Turner syndrome and was excluded from the overall analysis.

\section{MRI findings}

Information on MRI was available for 196 patients and is shown in Table 4 . Of them, 82 were reported to have some abnormality on imaging. In these patients, 26 had lesions that were considered to be acquired, 38 had lesions classified as developmental, and 18 had nonspecific or unclassified lesions. The developmental lesions included 23 malformations of cortical development. Significant differences between subgroups with respect to the CNV burden were not found (Supplementary Table 3).

\section{Dysmorphic features, MCAs}

In 207 patients the presence of dysmorphic features could be assessed, and were present in 72 patients. Information on the presence of MCAs was available for the same 207 patients; MCA was present in 19 patients. Out of 222 patients, 13 had microcephaly and 5 had macrocephaly. Patients with dysmorphic features had a significantly higher CNV burden (Supplementary Table 3). However, this difference was due to CNVs of unknown significance and likely pathogenic CNVs. All other differences between subgroups were not significant.

\section{Neurodevelopmental phenotypes}

Information on neurological examination was available for 168 patients, of whom 91 were considered neurologically abnormal. Information on speech development was available for 201 patients, of whom 131 were considered abnormal. Gross motor development could be assessed in 206 patients, of whom 110 had abnormal motor development. Information on intellectual functioning and intellectual disability was available for 172 patients. A total of 140 of these patients had at least moderate intellectual disability. Information on behavioral phenotypes was available for 81 individuals, of whom 38 were considered to have normal behavior. The subgroup for behavioral phenotypes was small owing to the difficulties in assessing distinct behavioral phenotypes in patients with intellectual disability. The comparison of CNV frequency between subgroups and different classes of CNVs did not show significant differences, except for a significant excess of CNVs of unknown significance in patients without ID or behavioral problems. This result is possibly due to the small number of patients investigated.

\section{Novel recurrent CNVs}

No novel recurrent CNVs larger than $100 \mathrm{~kb}$ were detected. However, inclusion of CNVs smaller than $100 \mathrm{~kb}$ revealed two patients (NL54 and NL55) with an overlapping duplication at 7q36.3, including part of the PTPRN2 gene (Supplementary Figure 1). However, as one 
Table 2 De novo variants identified in 11 patients

\begin{tabular}{|c|c|c|c|c|c|c|c|}
\hline$I D$ & Gender & $\begin{array}{l}\text { Electroclinical } \\
\text { syndrome }\end{array}$ & $\begin{array}{l}\text { Age of } \\
\text { onset }\end{array}$ & $\begin{array}{l}\text { Neurocognitive } \\
\text { phenotype }\end{array}$ & Dysmorphic features, MCA & $M R I$ & Genetic findings \\
\hline D5 & Male & $\begin{array}{l}\text { Myoclonic } \\
\text { astatic epilepsy }\end{array}$ & 3 Years & Mild ID & None & Normal & $16 p 13.11$ deletion \\
\hline D10 & Male & $\begin{array}{l}\text { Focal epilepsy, } \\
\text { unclassified }\end{array}$ & 5 Months & Severe ID & Macrocephaly & Hydrocephalus & 6q24.2q26 deletion \\
\hline D34 & Female & $\begin{array}{l}\text { Focal epilepsy, } \\
\text { unclassified }\end{array}$ & 24 Years & Profound ID & $\begin{array}{l}\text { Hyperteleorism, ptosis, } \\
\text { flat nasal bridge, low set } \\
\text { and small ears }\end{array}$ & Normal & 3pter3p25.2 deletion \\
\hline NL4 & Male & $\begin{array}{l}\text { Focal epilepsy, } \\
\text { unclassified }\end{array}$ & Unknown & $\begin{array}{l}\text { Motor and speech } \\
\text { delay, not classified }\end{array}$ & Microcephaly & $\begin{array}{l}\text { Paraventricular cyst right } \\
\text { temporal lobe }\end{array}$ & $17 p 11.2$ deletion \\
\hline NL5 & Female & $\begin{array}{l}\text { Epilepsy, } \\
\text { unclassified }\end{array}$ & 5 Years & Borderline ID & None & normal & $16 p 11.2$ deletion \\
\hline NL14 & Female & $\begin{array}{l}\text { Idiopathic gen- } \\
\text { eralized } \\
\text { epilepsy }\end{array}$ & 3 Years & Unknown & $\begin{array}{l}\text { Microcephaly, flat face with } \\
\text { full cheeks, clinodactyly of } \\
\text { fifth finger bilaterally }\end{array}$ & $\begin{array}{l}\text { Arachnoidal cyst left } \\
\text { temporal side }\end{array}$ & $5 p 11.2$ deletion \\
\hline NL31 & Female & $\begin{array}{l}\text { Focal epilepsy, } \\
\text { unclassified }\end{array}$ & 6 Months & ID NOS & None & Normal & 17p13.1 deletion \\
\hline NL32 & Male & $\begin{array}{l}\text { Epilepsy, } \\
\text { unclassified }\end{array}$ & 13 Years & ID NOS & None & $\begin{array}{l}\text { Progressive loss of white } \\
\text { and gray matter }\end{array}$ & 2q24.1 deletion \\
\hline NL37 & Male & $\begin{array}{l}\text { Lennox-Gastaut } \\
\text { syndrome }\end{array}$ & 6 Years & ID NOS & $\begin{array}{l}\text { Microcephaly, epicanthic folds, } \\
\text { almond-shaped palpebral fis- } \\
\text { sures, strabismus, micrognathia }\end{array}$ & $\begin{array}{l}\text { Atrophic corpus callosum, } \\
\text { delayed myelinization }\end{array}$ & $\begin{array}{l}\text { Xp22 deletion }{ }^{\mathrm{a}} \mathrm{Xq} 28 \\
\text { duplication }{ }^{\mathrm{a}} 6 \mathrm{p} 25 \text { deletion pat }\end{array}$ \\
\hline NL58 & Male & $\begin{array}{l}\text { Focal epilepsy, } \\
\text { unclassified }\end{array}$ & 5 Years & Borderline ID & None & Normal & $\begin{array}{l}\text { 5q35.2 duplication }{ }^{\mathrm{b}} 17 p 13.1 \\
\text { deletion mat }\end{array}$ \\
\hline NL74 & Male & $\begin{array}{l}\text { Epilepsy, } \\
\text { unclassified }\end{array}$ & 9 Months & ID NOS & None & $\begin{array}{l}\text { Nonspecific white matter } \\
\text { abnormalities }\end{array}$ & $13 q 13.3$ deletion \\
\hline
\end{tabular}

Abbreviations: MCA, multiple congenital anomaly; MRI, magnetic resonance image; ID NOS, intellectual disorder not otherwise specified.

aThe mother of the proband carries an X-chromosomal pericentric inversion. The rearrangements are de novo, but due to the rearrangement in the mother.

${ }^{\mathrm{b}} \mathrm{De}$ novo duplication considered as likely pathogenic according to Miller et al. ${ }^{10}$

Table 3 Clinical features of patients carrying a known pathogenic CNV

\begin{tabular}{|c|c|c|c|c|c|c|c|}
\hline Patient ID & $\begin{array}{l}\text { Electroclinical } \\
\text { syndrome }\end{array}$ & Development & Dysmorphic features & $M C A$ & Neuro & $M R I$ & CNV \\
\hline NL43 & CSWS & $\begin{array}{l}\text { Motor and speech delay, } \\
\text { IQ75 }\end{array}$ & None & None & Normal & $\begin{array}{l}\text { Arachnoidal cyst, caudal } \\
\text { vermis hypoplasia }\end{array}$ & Dup 1q21.1 \\
\hline NL59 & Unclassified & Mild developmental delay & None & None & Hypertonia & Normal & Del $15 q 11.2$ \\
\hline NL62 & BFNS & normal & None & None & Normal & Hormal & Del $15 q 11.2$ \\
\hline NL3 & IGE & $\begin{array}{l}\text { Moderate to severe mental } \\
\text { retardation }\end{array}$ & $\begin{array}{l}\text { Macrocephaly, facial } \\
\text { dysmorphisms }\end{array}$ & None & unknown & Not performed & $\begin{array}{l}\text { Del } 15 q 13.1>15 q 13.2 \\
\text { and Del } 15 q 13.3\end{array}$ \\
\hline NL5 & Unclassified & Speech delay, IQ 76 & None & None & Normal & Normal & Del 16p11.2 de novo \\
\hline NL68 & Unclassified & Speech delay & None & None & Normal & Not performed & Del 16p11.2 \\
\hline NL17 & IGE & $\begin{array}{l}\text { Moderate mental } \\
\text { retardation }\end{array}$ & $\begin{array}{l}\text { Short stature, flat } \\
\text { midface }\end{array}$ & None & Normal & Not performed & Del 16p13.11 \\
\hline D5 & MAE & Mild cognitive disorder & None & None & Normal & Normal & Del 16p13.11 de novo \\
\hline NL64 & IGE & $\begin{array}{l}\text { Normal psychomotor } \\
\text { development, autism }\end{array}$ & None & None & Normal & Normal & Dup 16p13.11 \\
\hline NL19 & IGE & Speech delay & $\begin{array}{l}\text { Short palpebral } \\
\text { fissures }\end{array}$ & $\begin{array}{l}\text { Abnormal place- } \\
\text { ment of anus }\end{array}$ & Normal & Normal & Del 22q11.2 \\
\hline NL4 & $\begin{array}{l}\text { Symptomatic } \\
\text { focal epilepsy }\end{array}$ & $\begin{array}{l}\text { Motor and speech delay, } \\
\text { not classified }\end{array}$ & Microcephaly & None & $\begin{array}{l}\text { Muscular } \\
\text { hypotonia }\end{array}$ & $\begin{array}{l}\text { Paraventricular cyst in } \\
\text { right temporal lobe }\end{array}$ & Del $17 p 11.2$ \\
\hline
\end{tabular}

Abbreviations: BFNS, benign familial neonatal seizures; CNV, copy number variation; CSWS, continuous spike wave in slow wave sleep; IGE, idiopathic generalized epilepsy; MAE, myoclonic astatic epilepsy; MCA, multiple congenital anomaly; MRI, magnetic resonance image; Neuro, Neurological examination.

duplication was intronic and as structural variants in other parts of the gene are found in controls, the pathogenic role of these duplications is questionable. Furthermore, we screened the sample for overlapping reciprocal CNVs, that is, deletions and duplications in the same region. Patients NL39 and NL66 both had a $\mathrm{CNV}$ in chromosomal band 9p24.3. The smallest overlap region contained a single gene, SMARCA2, which has recently been associated with Nicolaides-Baraitser syndrome ${ }^{14}$ (Supplementary Figure 2). However, duplications in other parts of this gene have been found as benign variants, raising issues regarding the pathogenicity of these variants.

\section{DISCUSSION}

In our study, we investigated the role of structural genomic variation in a sample of patients with rare epilepsies with complex phenotypes including patients with various MRI findings, dysmorphic features, developmental disorders, and MCAs. This sample allowed us to investigate the frequency of $\mathrm{CNVs}$ in epilepsies with complex 
Table 4 Classification of MRI findings

\begin{tabular}{|c|c|}
\hline Type of lesion & $\mathrm{n}$ \\
\hline \multicolumn{2}{|l|}{ Acquired lesions } \\
\hline MTS & 9 \\
\hline PVL & 5 \\
\hline Gliosis after asphyxia & 3 \\
\hline Rasmussen's encephalitis & 2 \\
\hline Other lesions classified as acquired & 7 \\
\hline \multicolumn{2}{|l|}{ Developmental lesions } \\
\hline \multicolumn{2}{|l|}{ Malformations of cortical development } \\
\hline \multicolumn{2}{|l|}{ Focal cortical dysplasia unilateral } \\
\hline \multicolumn{2}{|l|}{ Polymicrogyria } \\
\hline \multicolumn{2}{|l|}{ Hemimegalencephaly } \\
\hline \multicolumn{2}{|l|}{ Transmantle dysplasia } \\
\hline \multicolumn{2}{|l|}{ Hippocampal malrotation } \\
\hline \multicolumn{2}{|l|}{ Lissencephaly } \\
\hline \multicolumn{2}{|l|}{ Schizencephaly } \\
\hline \multicolumn{2}{|l|}{ Holoprosencephaly } \\
\hline \multicolumn{2}{|l|}{ Subependymal noduli } \\
\hline \multicolumn{2}{|l|}{ Megalencephaly } \\
\hline \multicolumn{2}{|l|}{ Other developmental abnormalities } \\
\hline \multicolumn{2}{|l|}{ Delay in myelinisation/hypomyelinisation } \\
\hline \multicolumn{2}{|l|}{ Atrophy } \\
\hline \multicolumn{2}{|l|}{ Paraventricular or arachnoidal cysts } \\
\hline \multicolumn{2}{|l|}{ Cerebellar hypoplasia, Chiari-II-malformations } \\
\hline \multicolumn{2}{|l|}{ Other } \\
\hline \multicolumn{2}{|l|}{ Non-specific, unclassified findings } \\
\hline \multicolumn{2}{|l|}{ Nonspecific ventricular enlargement } \\
\hline Nonspecific white matter abnormalities & \\
\hline Other & \\
\hline
\end{tabular}

Abbreviations: MRI, magnetic resonance image; MTS, mesial temporal sclerosis; PVL, periventricular leukomalacia.

phenotypes with and without additional features. We found a high frequency of rare CNVs in approximately $30 \%$ of patients with or without abnormal MRI findings, indicating that the overall frequency of rare CNVs does not depend on the presence of MRI findings. These results also apply when different classes of CNVs (unknown significance, likely pathogenic, pathogenic, de novo) are taken into consideration. This observation suggests that structural genomic variations have a role in a larger group of epilepsies than previously anticipated, including seizure disorders with various degrees of imaging abnormalities. We observed a higher frequency of CNVs in patients with dysmorphic features and/or MCAs.

The observed rate of rare CNVs in patients with epilepsies and complex phenotypes is slightly lower as compared with those observed in patients with intellectual disability and autism, but is higher than expected in control cohorts. Cooper et al. reported a frequency of rare $\mathrm{CNVs} \geq 400 \mathrm{~kb}$ in $25.7 \%$ of 15767 patients with intellectual disability compared with $11.5 \%$ in 8329 controls, ${ }^{15}$ a difference that was even more pronounced with increasing CNV size - for example, $11.3 \%$ in cases versus $0.6 \%$ in controls for CNVs $\geq 1.5 \mathrm{Mb}$. In our sample, $17.5 \%$ of patients had CNVs larger than $400 \mathrm{~kb}$ with $6.3 \%$ of patients carrying CNVs larger than $1.5 \mathrm{Mb}$. The differences in the frequencies of CNVs in our sample and published controls are significant both at the $400 \mathrm{~kb}$ level $(P=0.007)$ and at the $1.5 \mathrm{Mb}$ level $(P<0.001)$. This comparison suggests an attributable risk of $6.2 \%$ for $\mathrm{CNVs}>400 \mathrm{~kb}$ and $5.7 \%$ for $\mathrm{CNVs}>1.5 \mathrm{Mb}$. This finding is intriguing, implying that the attributable risk is largely due to the influence of larger CNVs.
In a significant number of patients a de novo variant could be confirmed. Three patients had de novo deletions consistent with known genomic disorders, including a microdeletion in 16p13.11 (D5), 16p11.2 (NL5), and 17p11.2 (NL4), the region implicated in SMS. In addition, two patients had terminal deletion syndromes including a terminal deletion of 6q (D10) and a terminal deletion of $3 p$ (D34). Both deletions were the two largest deletions in our sample, exceeding $10 \mathrm{Mb}$. Epilepsy in $6 \mathrm{q}$ terminal deletion syndrome is a welldescribed feature, ${ }^{16,17}$ whereas intellectual disability is usually the most prominent feature in $3 \mathrm{p}$ deletion syndrome. ${ }^{18,19}$ As parents were not available for a significant proportion of patients, the frequency of de novo variants might be an underestimation.

In five patients with a rare CNV, a monogenic cause of the epilepsy was also present. This illustrates that the presence of a CNV does not preclude the possibility of a monogenic cause of the epilepsy. In children with epilepsy and developmental delay, array-CGH is often performed early in the process of etiological evaluation. When CNVs are found that may explain the epilepsy, monogenic causes can easily be overlooked. ${ }^{20}$

We found three regions with overlapping CNVs in more than one patient, at 16p13.11, 7q36.3, and 9p23. The CNVs at 16p13.11 further limit the epilepsy candidate genes in this region to $A B C C 1$ and $A B C C 6$. Both genes are members of the MRP subfamily and have a role in multi-drug resistance.

The two other overlapping copy number variants at $7 q 36.3$ and 9p23 identified in our sample did not delineate novel disease genes, as both candidate genes (PTPRN2 and SMARCA2) also contained a large number of benign duplications and deletions.

We did not observe significant group differences between patients with or without MRI findings, independent of the class of CNV investigated. In particular, several patients with known MRI abnormalities had genetic findings, which might contribute to the overall phenotype. In patient NL4, MRI revealed a paraventricular cyst in the right temporal lobe that was considered causal for underlying focal epilepsy by the treating physician. However, genetic analysis identified a 17p11.2 microdeletion, consistent with SMS. Epilepsy is a welldescribed feature of SMS. Although we are unable to clearly attribute the patient's epilepsy to the developmental MRI abnormality or to the de novo microdeletion, this case illustrates that even the presence of causally implicated MRI findings should not preclude genetic analysis. Similar arguments have been raised in patients with temporal lobe epilepsy, in which a significant subset of patients with resective surgery and good postoperative outcome carry large CNVs. ${ }^{21}$

The patient sample included in our study is a mixed sample from three different centers with different backgrounds and is not population-based. In fact, it was the impetus of the investigation to assess $\mathrm{CNV}$ frequencies in patients not otherwise included in other welldefined epilepsy cohorts. This inclusion strategy might have confounded risk estimation and $\mathrm{CNV}$ frequencies. However, as baseline characteristics, for example, the overall $\mathrm{CNV}$ frequency, are in line with published data, we assume that the effect of our inclusion strategy would not have significantly biased the results.

\section{Recommendations for clinical practice}

We describe the frequency and the 'genetic landscape ${ }^{15}$ of CNVs in a diverse sample of patients with rare epilepsies and complex phenotypes, including in patients with a diverse phenotypic spectrum. The high frequency of CNVs irrespective of clinical phenotype indicates that screening for CNVs has the potential to identify relevant etiological genetic factors across a wide range of diverse epilepsies, independent of preexisting abnormalities. 
This suggests that array-CGH or SNP arrays may represent a powerful first-line screening tool in diverse epilepsy syndromes and should not be limited to epilepsies that are commonly assumed to be genetic. Array-CGH may also identify additional possibly pathogenic variants in known monogenic epilepsies, particularly if the phenotype has additional clinical features.

The structural genomic variants described in this publication have been submitted to the Database of Genomic Variants Archive (http:// www.ebi.ac.uk/dgva/, accession number estd208).

\section{CONFLICT OF INTEREST}

The authors declare no conflict of interest.

\section{ACKNOWLEDGEMENTS}

We thank the patients and their parents for participation in this study. This project was supported by the EuroEPINOMICS projects within the EUROCORES framework of the European Science Foundation and funds of the German Research Foundation (DFG HE 5413/3-1).

1 Helbig I, Scheffer IE, Mulley JC, Berkovic SF: Navigating the channels and beyond: unravelling the genetics of the epilepsies. Lancet Neurol 2008; 7: 231-245.

2 Proposal for revised classification of epilepsies and epileptic syndromes. Commission on Classification and Terminology of the International League Against Epilepsy. Epilepsia 1989; 30: 389-399.

3 Berg AT, Berkovic SF, Brodie MJ et al: Revised terminology and concepts for organization of seizures and epilepsies: report of the ILAE Commission on Classification and Terminology, 2005-2009. Epilepsia 2010; 51: 676-685.

4 Mefford HC, Muhle $\mathrm{H}$, Ostertag $\mathrm{P}$ et al: Genome-wide copy number variation in epilepsy: novel susceptibility loci in idiopathic generalized and focal epilepsies. PLoS Genet 2010; 6: e1000962.

5 Heinzen EL, Radtke RA, Urban TJ et al: Rare deletions at $16 \mathrm{p} 13.11$ predispose to a diverse spectrum of sporadic epilepsy syndromes. Am J Hum Genet 2010; 86: 707-718.
6 de Kovel CG, Trucks H, Helbig I et al: Recurrent microdeletions at 15q11.2 and $16 \mathrm{p} 13.11$ predispose to idiopathic generalized epilepsies. Brain 2010; 133 : 23-32.

7 Helbig I, Mefford HC, Sharp AJ et al: 15q13.3 microdeletions increase risk of idiopathic generalized epilepsy. Nat Genet 2009; 41: 160-162.

8 Itsara A, Cooper GM, Baker C et al: Population analysis of large copy number variants and hotspots of human genetic disease. Am J Hum Genet 2009; 84: $148-161$.

9 Barkovich AJ, Kuzniecky RI, Jackson GD, Guerrini R, Dobyns WB: A developmental and genetic classification for malformations of cortical development. Neurology 2005; 65: 1873-1887.

10 Miller DT, Adam MP, Aradhya S et al: Consensus statement: chromosomal microarray is a first-tier clinical diagnostic test for individuals with developmental disabilities or congenital anomalies. Am J Hum Genet 2010; 86: 749-764.

11 Mefford HC, Eichler EE: Duplication hotspots, rare genomic disorders, and common disease. Curr Opin Genet Dev 2009; 19: 196-204.

12 Hannes FD, Sharp AJ, Mefford HC et al: Recurrent reciprocal deletions and duplications of 16p13.11: the deletion is a risk factor for MR/MCA while the duplication may be a rare benign variant. J Med Genet 2009; 46: 223-232.

13 Weiss LA, Shen Y, Korn JM et al: Association between microdeletion and microduplication at 16p11.2 and autism. N Engl J Med 2008; 358: 667-675.

14 Van Houdt JK, Nowakowska BA, Sousa SB et al: Heterozygous missense mutations in SMARCA2 cause Nicolaides-Baraitser syndrome. Nat Genet 2012; 44: 445-449.

15 Cooper GM, Coe BP, Girirajan S et al: A copy number variation morbidity map of developmental delay. Nat Genet 2011; 43: 838-846.

16 Striano P, Malacarne M, Cavani S et al: Clinical phenotype and molecular characterization of $6 \mathrm{q}$ terminal deletion syndrome: Five new cases. Am J Med Genet A 2006; 140: 1944-1949.

17 Elia M, Striano P, Fichera $M$ et al: $6 \mathrm{q}$ terminal deletion syndrome associated with a distinctive EEG and clinical pattern: a report of five cases. Epilepsia 2006; 47: 830-838.

18 Malmgren H, Sahlen S, Wide K, Lundvall M, Blennow E: Distal 3p deletion syndrome: detailed molecular cytogenetic and clinical characterization of three small distal deletions and review. Am J Med Genet A 2007; 143A: 2143-2149.

19 Fernandez TV, Garcia-Gonzalez IJ, Mason CE et al: Molecular characterization of a patient with $3 p$ deletion syndrome and a review of the literature. Am J Med Genet $A$ 2008; 146A: 2746-2752.

20 Poot M, van der Smagt JJ, Brilstra EH, Bourgeron T: Disentangling the myriad genomics of complex disorders, specifically focusing on autism, epilepsy, and schizophrenia. Cytogenet Genome Res 2011; 135: 228-240.

21 Catarino CB, Kasperaviciute D, Thom M et al: Genomic microdeletions associated with epilepsy: not a contraindication to resective surgery. Epilepsia 2011; 52: $1388-1392$.

Supplementary Information accompanies this paper on European Journal of Human Genetics website (http://www.nature.com/ejhg) 